JPCS

Peqguruang: Conference Series

Vol. 2 No. 2 Nov. 2020

elSSN: 2686-3472

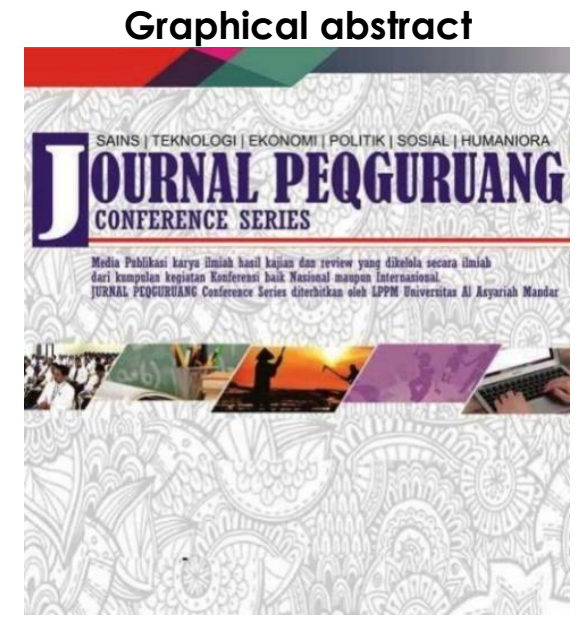

\title{
EFEKTIVITAS PENGELOLAAN BADAN USAHA MILIK DESA DI DESA SATANETEAN KECAMATAN SESENAPADANG KABUPATEN MAMASA
}

${ }^{1}$ Arruan Tudang, ${ }^{2}$ Abdul Khalik, ${ }^{3}$ Abdul Muttalib

Program Ilmu Pemerintahan, Fakultas Pemerintahan, Universitas Al Asyariah Mandar

1arruantudang10@gmail.com

2alifbatza@gmail.com

\begin{abstract}
The purpose of this research is to find out how the BUMDes management of the village in Satanetean Village, Sesenapadang District, Mamasa Regency. As well as providing an overview of supporting factors and inhibiting factors in the management of the BUMDes Program. The research was conducted in Satanetean Village, Sesenapadang sub-district, Mamasa Regency.

This research uses a descriptive qualitative approach. This is considered in accordance with the purpose of the study with the intention of describing, describing and intending to interpret problems related to the role of BUMDes to increase the village's original income, based on observations of the facts that occur in the field. BUMDes management is also mandated in Law No. 6 of 2014 that villages must establish BUMDes to build the economic independence of village communities.

The results of this study can be concluded that in general the presence of BUMDES in Satanetean Village can be felt to have benefits for the community. The issuance of Permendes Number 4 of 2015 is a legal umbrella for developing BUMDES management. sufficient to run BUMDES. The inhibiting factor in managing BUMDES is the lack of capacity owned by BUMDES managers and the absence of adequate capital support from the Village Government
\end{abstract}

Keywords: Effectiveness, Management.

\begin{abstract}
Abstrak
Tujuan penelitan adalah untuk mengetahui bagaiman pengeloaan BUMDes desa di Desa Satanetean Kecamatan Sesenapadang Kabupaten Mamasa. Serta memberikan gambaran faktor pendukung dan faktor penghambat dalam pengelolaan Program BUMDes.

Penelitian ini menggunakan pendekatan kualitatif yang bersifat deskriptif. Hal ini dianggap sesuai dengan tujuan penelitian dengan maksud menggambarkan, mendeskripsikan dan bermaksud menginterpretasi masalah yang berkaitan dengan peran BUMDes untuk meningkatkan pendapatan asli desa, berdasarkan pengamatan atas fakta yang terjadi di lapangan. Pengelolaan BUMDes juga diamanatkan dalam Undang-Undang Nomor 6 Tahun 2014 bahwa desa harus mendirikan BUMDes untuk membangun kemandirian ekonomi masyarakat desa.

Hasil penelitian ini dapat disimpulkan bahwa secara umum keberadaan BUMDES di Desa Satanetean dapat dirasakan memiliki manfaat bagi masyarakat. Terbitnya Permendes Nomor 4 Tahun 2015 menjadi payung hukum untuk mengembangkan pengelolaan BUMDES. Faktor pendukung di dalam pengelolaan BUMDES adalah banyaknya potensi sumber daya alam serta adanya regulasi yang cukup untuk menjalankan BUMDES. Faktor penghambat dalam pengelolaan BUMDES adalah kurangnya kapasitas yang dimiliki oleh pengelola BUMDES dan tidak adanya dukungan penyertaan modal yang cukup dari Pemerintah Desa
\end{abstract}

Kata Kunci : Efektivitas, Pengelolaan.

Article history

DOI: http://dx.doi.org/10.35329/ip.v2i2.1556

Received : 07 September 2020 | Received in revised form : 17 September 2020 | Accepted :03 Oktober 2020 


\section{PENDAHULUAN}

Kelancaran pelaksanaan pemerintahan dan keberhasilan pembangunan nasional di semua bidang, baik fisik maupun mental, dalam mencapai tujuan pembangunan sangat tergantung pada birokrasi pemerintah dan optimalisasi pelaksanaan program pembangunan. Kabupaten Mamasa sebagai daerah otonom menyadari bahwa ini adalah salah satu pekerjaan rumah yang perlu dilakukan secara bertahap dan berkelanjutan, dan juga merupakan kekuatan pendorong bagi pemerintah daerah dalam melakukan tugas pemerintahan mereka. Untuk mendorong pertumbuhan ekonomi di desa, program BUMDes dibentuk.

Dasar untuk melakukan penelitian adalah bahwa administrasi dana desa tetap mendesak, menunjukkan bahwa peran pemerintah desa sangat penting dalam memberikan pengawasan yang optimal untuk mencapai hasil yang memuaskan, hanya saja masih terkait kelemahan. dengan budaya kolusi antara regulator dan subjek pengawasan di sana. Meskipun peran pemerintah desa dalam pembinaan belum optimal, hal ini dapat dilihat dalam realisasi pengembangan bentuk-bentuk BUMDes yang tidak dilaksanakan dan sosialisasi masyarakat yang kurang merata. terutama yang terkait dengan pengembangan formulir BUMDes. Pembangunan pedesaan juga dapat dilihat sebagai program pembangunan yang dilaksanakan dalam rencana untuk meningkatkan produksi, pendapatan, dan kemakmuran dalam hal meningkatkan kualitas hidup dalam pendidikan, kesehatan dan perumahan.

Oleh karena itu, aplikasi ini diharapkan menjadi upaya untuk merangsang dan menggerakkan roda perekonomian pedesaan. Salah satu upaya yang dapat dilakukan adalah merangsang pergerakan ekonomi pedesaan melalui kewirausahaan pedesaan yang terkandung dalam BUMD yang dikembangkan oleh masyarakat desa. Fasilitas BUMDes diatur oleh Pasal 213 (1) UU No. 32 2004, yang memungkinkan desa untuk mendirikan BUMDes sesuai dengan kebutuhan dan kemampuan desa. Artinya bahwa dalam undangundang tersebut menegaskan tentang janji pemenuhan permintaan dan konteks pembangunan tingkat desa (Alam, S., Rahayu, A., \& Nurdina, N, 2021).

Hal ini juga diatur dalam Peraturan Pemerintah No. 72 tahun 2005 tentang desa dan Peraturan Desa No. 4 tahun 2015 tentang BUMDes. BUMDes adalah unit bisnis di mana semua atau sebagian besar modal dimiliki oleh desa, dengan aset desa yang terlibat langsung untuk mengelola aset, layanan, dan bisnis lainnya untuk kesejahteraan maksimum masyarakat desa.

Untuk meningkatkan kesejahteraan masyarakat, desa melalui BUMDes harus merevolusi kualitas hidup masyarakat sebagai objek pembangunan di desa, sehingga untuk mewujudkan ekonomi masyarakat desa, diperlukan tata kelola untuk meningkatkan ekonomi masyarakat pedesaan. Berdasarkan uraian latar belakang, peneliti menyimpulkan studi ini dengan fokus pada "Efektivitas manajemen kewirausahaan Desadi di Desa Satanetean, Distrik Sesenapadang, Kabupaten Mamasa".

\section{METODE PENELITIAN}

Penelitian ini dilakukan di Desa Satanetean, Kecamatan Sesenapadang, Kabupaten Mamasa. Peneliti memilih desa ini sebagai objek penelitian karena peneliti dapat lebih mudah mengakses pengamatan dari objek penelitian. Studi ini dilakukan dari 5 Februari hingga 30 Maret 2020.

Penelitian ini menggunakan pendekatan kualitatif yang bersifat deskriptif. Hal ini dianggap konsisten dengan tujuan penelitian dengan maksud untuk mendeskripsikan, menggambarkan dan menafsirkan masalah yang berkaitan dengan peran BUMDES dalam meningkatkan pendapatan asli desa berdasarkan pengamatan fakta yang terjadi di desa. daerah.

Adapun Informan yang diyakini dapat memberikan data atau informasi yang tepat dan akurat dalampenelitian ini adalah sebagai berikut:
1. Kepala Desa 1 Orang
2. Ketua BUMDes Desa Satanetean 1 Orang
3. Ketua BPD Desa Satanetean 1 Orang
4. Tokoh Agama 1 orang
5. Tokoh Masyarakat 1 Orang
6. Tokoh Pemuda 1 Orang
Jumlah Semua Responde 6 orang

Sejalan dengan pandangan ini, penulis menyimpulkan bahwa alat dalam penelitian ini adalah peneliti yang didukung oleh alat seperti perekam suara, kamera, alat tulis, dan pedoman wawancara. Pedoman wawancara digunakan agar wawancara yang dilakukan tidak menyimpang dari tujuan penelitian. Pedoman ini tidak hanya didasarkan pada tujuan penelitian, tetapi juga pada teori yang terkait dengan masalah yang diselidiki. Selain itu, pedoman wawancara digunakan sebagai bahan untuk menulis hasil penelitian, karena jika peneliti hanya mengandalkan kapasitas memori, peneliti sangat khawatir bahwa data yang sudah diterima akan dilupakan. Penggunaan model wawancara, tentu saja, disesuaikan dengan keberadaan data di bidang yang dibutuhkan peneliti. Oleh karena itu, sejumlah pertanyaan telah diajukan sebelumnya untuk wawancara terstruktur dengan mengklasifikasikan bentuk pertanyaan. Guba dan Lincoln mengklasifikasikan jenis pertanyaan yang akan disiapkan dalam wawancara penelitian

Setelah data dikumpulkan dari hasil pengamatan data, analisis data dilakukan untuk mengolah data. Analisis data adalah proses pengorganisasian dan pemilahan data ke dalam pola, kategori, dan unit deskripsi dasar sehingga topik dan hipotesis kerja dapat ditemukan, seperti yang disarankan oleh data (Moleong, 2002: 103). Analisis data bersifat induktif, mulai dari lapangan atau fakta empiris, dengan menenggelamkan diri di lapangan, mempelajari, menganalisis, 
menafsirkan, dan menarik kesimpulan dari fenomena di lapangan.

\section{HASIL DAN PEMBAHASAN}

\section{A. Hasil Penelitian}

Dari penelitian ini, ditujukan untuk mengetahui pelaksanaan pembagian warisan menurut hukum adat di desa marampan kecamatan sesenapadang kabupaten Mamasa. informasi yang diperoleh dari pengamatanberikut ini adalah data yang terkumpul berdasarkan penelitian yang dilakukan dengan melakukan wawancara kepada responden yang bertujuan untuk memperoleh informasi dan mendapatkan data-data dengan melakukan diaolog kepada responden secara lisan.

Pengamatan teersebut adalah penelitian dengan menggunakan pendekatan yuridis empiris yaitu penelitian dengan menggunakan pendekatan hukum dalam menggambarkan fenomena yang terjadi. Aspek sosiologis yang diamati yaitu adanya persoalan perilaku yang tumbuh dan berkembang di desa Marampan

\section{Gambaran Umum Lokasi Penelitian}

Ketersediaan potensi yang dimiliki desa dalam hal sumber daya manusia dan alamnya adalah tujuan pembangunan ekonomi yang harus berjalan secara paralel. Dalam menilai kemajuan manajemen BUMDes, metode ini didukung oleh partisipasi dan kegiatan produktif masyarakat, sehingga keberhasilan pembangunan ekonomi dapat diukur sesuai dengan arah strategi pembangunan desa. Karakter yang harus dimiliki desa dalam mengelola sumber dayanya harus dilihat dari berbagai sudut pandang, termasuk kondisi geografis, demografis, dan ekonomi.

\section{Kondisi geografis dan demografis}

Desa Satanetean adalah salah satu desa di Kecamatan Sesenapadang yang mempunyai luas wilayah $39 \mathrm{Ha}$. Jumlah penduduk Desa Ciawitali sebanyak 1485 Jiwa. Sedangkan jumlah Keluarga Miskin (Gakin) $221 \mathrm{KK}$ dengan persentase $41,31 \%$ dari jumlah keluarga yang ada di Desa Satanetean.

Batas-batas administratif pemerintahan Desa Satanetean Kecamatan Sesenapadang sebagai berikut:

$\begin{array}{llll}\text { - Sebelah Utara } & : & \text { Desa Bombong Lambe } \\ \text { - Sebelah } & : & \text { Desa Osango } \\ \text { Timur } & \text { Sebelah } & \text { Desa Orobua Selatan } \\ \text { Selatan } & & \\ \text { - Sebelah Barat } & : & \text { Desa Lembana Salulo }\end{array}$

Dilihat dari topografi dan kontur tanah, Desa Satanetean Kecamatan Sesenapadang secara umum berupa Persawahan dan Perbukitan yang berada pada ketinggian antara $90 \mathrm{M}$ s/d $100 \mathrm{M}$ di atas permukaan laut dengan suhu rata-rata berkisar antara $20^{\circ} \mathrm{s} / \mathrm{d} 24^{0}$ Celcius. Desa SATANETEAN terdiri dari 4 (Tiga) Dusun, 6 (Enam). Orbitasi dan waktu tempuh dari ibukota kecamatan $5 \mathrm{~km}^{2}$ dengan waktu tempuh 120 menit (jalan Kaki) dan dari ibukota kabupaten $4 \mathrm{~km}^{2}$ dengan waktu tempuh 10 menit (Kendaraan).

Mata Pencaharian

Mata pencaharian penduduk Desa SATANETEAN KECAMATAN SESENAPADANG terdiri dari:

- Petani

- Buruh Tani

215 orang

- Pedagang

272 orang

- PNS

28 orang

- TNI/Polri

- Karyawan Swasta

- Wirausaha lainnya

4 orang

1 orang

- orang

15 orang

\section{Sarana Pendidikan}

Sarana pendidikan umum yang terdapat di Desa SATANETEAN KECAMATAN SESENAPADANG meliputi:

$\begin{array}{ll}\text { - Taman Kanak- } & - \text { buah } \\ \text { kanak/PAUD } & \\ \text { - Sekolah Dasar (SD) } & 2 \text { buah } \\ \text { - SLTP/MTs } & - \text { buah } \\ \text { - SLTA/SMK } & - \text { buah } \\ \quad \text { Sedangkan jumlah tenaga } & \text { pengajar terdiri } \\ \text { dari : } & - \text { orang } \\ \text { - Taman Kanak-kanak/PAUD } & \text { 14 orang } \\ \text { - Sekolah Dasar (SD) } & \text { - orang } \\ \text { - SLTP/MTs } & - \text { orang } \\ \text { - SLTA/SMK } & \end{array}$

Sarana Kesehatan

Sarana kesehatan yang ada di Desa SATANETEAN meliputi:

- Puskesmas

- Puskesmas Pembantu

- Polindes

- Balai Pengobatan/Klinik

- Dokter Umum

- Posyandu

- Pos KB Desa

- Bidan

- Petugas Gizi Keliling

- Dukun Bayi terlatih

Sarana dan Prasarana Ekonomi

- Bank

- Koperasi Unit Desa

- Pasar

- BUMDES

- Industri Rumah Tangga

- Perusahaan Kecil

- Perusahaan Sedang

- Perusahaan Besar
- buah

1 buah

1 buah

- buah

- orang

3 buah

1 buah

1 orang

5 orang

2 orang

- buah

1 buah

- buah

1 buah

2 buah

2 buah

- buah

- buah 


\section{PEMBAHASAN}

Pengelolaan Badan Usaha Milik Desa (BUMDes) di Desa Satanetean Kecamatan Sesenaadang Kabupaten Mamasa

Asosiasi Menteri Desa nomor 4 tahun 2015 tentang pendirian, pengelolaan dan pembubaran BUMDesa Pasal 7 menyatakan bahwa BUMDesa terdiri dari unit bisnis dengan badan hukum yang baik, yang dikelola oleh BUMDesa dan juga pemerintah kota. Manajemen BUMDes di desa Satanetan mencakup strategi kegiatan untuk memperkuat masyarakat desa. Untuk membuka potensi para penduduk desa setan, dianggap penting bahwa BUMDesa dalam bentuknya mendukung proses pertumbuhan ekonomi masyarakat dengan membantu masyarakat desa, hasil pertanian, dan keterampilan kreatif masyarakat desa dalam melaksanakan proses ekonomi. dari Komunitas untuk memperhitungkan.

Manajemen BUMDes juga diwajibkan oleh UU No. 6 tahun 2014 bahwa desa harus membentuk BUMDes untuk memperkuat kemandirian ekonomi masyarakat desa. Dengan yayasan ini, pemerintah desa setan mendirikan BUMDes sebagai perpanjangan dari pemerintah desa untuk mengendalikan pembangunan ekonomi desa. Potensi yang dapat dituju oleh manajemen BUMD Desa Satanetan adalah produk pertanian, kerajinan tangan, ternak, dan juga potensi wisata alam. Potensi ini menjadi tujuan dari program area bisnis di desa Satanetean sebagai bagian dari pengelolaan keberadaan BUMDes.

Sebagai langkah dalam pengelolaan sumber daya desa Setan untuk meningkatkan pertumbuhan dan kesejahteraan masyarakat melalui kegiatan produktivitas masyarakat di berbagai bidang, yaitu pertanian, peternakan, kerajinan tangan dan potensi penggunaan wisata alam, sebagai alat yang adil untuk kesejahteraan masyarakat desa dan sebagai forum yang mengatur hasil industri Pertanian dan kegiatan masyarakat produktif lainnya menjadi kebutuhan masyarakat luas.

\section{Faktor Pendukung dan Faktor Penghambat Pengelolaan BUMDES}

Faktor Pendukung

Dari hasil penelitian yang dilakukan ditemukan bahwa yang menjadi pendukung dalam pengelolaan BUMDES di Desa Satanetean adalah:

1) Potensi sumber daya alam yang dimiliki oleh masyarakat di Desa Satanetean;

2) Regulasi dalam pengelolaan BUMDES.

Faktor Penghambat

Yang menjadi faktor penghambat dalam pengelolaan BUMDES di Desa Satanetean adalah:

1) Kapasitas pengelola BUMDES yang masih rendah.

2) Tidak adanya dukungan penyertaan modal yang cukup dari Pemerintah Desa

\section{SIMPULAN}

Berdasarkan hasil penelitian yang telak ditemukan oleh peneliti dapat disimpulkan sebagai berikut:

1) Secara umum keberadaan BUMDES di Desa Satanetean dapat dirasakan memiliki manfaat bagi masyarakat. Terbitnya Permendes Nomor 4 Tahun 2015 menjadi payung hukum untuk mengembangkan pengelolaan BUMDES.

2) Faktor pendukung di dalam pengelolaan BUMDES adalah banyaknya potensi sumber daya alam serta adanya regulasi yang cukup untuk menjalankan BUMDES.

3) Faktor penghambat dalam pengelolaan BUMDES adalah kurangnya kapasitas yang dimiliki oleh pengelola BUMDES dan tidak adanya dukungan penyertaan modal yang cukup dari Pemerintah Desa

Dengan kesimpulan di atas, peneliti merekomendasikan saran-saran berikut:

BUMDes sebagai salah satu lembaga pemberdayaan masyarakat desa tidak hanya berfokus pada potesi-potesi yang dimilki desa tetapi, tetapi pencapaian efetivitas pengelolan menjadi ukuran yang dapat memberi daya manfaat bagi masyarakat desa. Dengan adaya peran poraktif masyarakat dengan kegiatan produktif yang dilakukan juga pelatihan kegiatan BUMDes sangat penting dilakukan agar dapat menunjang tercapainya tujuan dalam pembangunan ekonomi desa. Pemahaman masyarakat terhadap BUMDes sangat penting terkait program-program kerja yang ditetapkan dan akan dijalankan sangat petig untuk diketahui masyarakat agar dapat merasakan asas masfaat kehadiran BUMDes.

Peningkatan efektivitas manajemen BUMDes di Desa Satanetean belum dinilai dalam hal kapasitas sumber daya manusia, dalam hal peran BUMDes dalam membangun dan memahami manajemen, dan dalam penerapan konsep manajemen yang menjadi ciri Desa Satanetan pendekatan adaptasi.

\section{DAFTAR PUSTAKA}

Alam, S., Rahayu, A., \& Nurdina, N. (2021, June). EFEKTIVITAS BADAN USAHA MILIK DESA (BUMDES) DALAM MENINGKATKAN OTONOMI DESA TAMMANGALLE KECAMATAN BALANIPA. In Journal Peqguruang: Conference Series (Vol. 2, No. 2).

Moleong, L.J. 2002. Metodologi Penelitian Kualitatif. Bandung: PT.Remaja

Undang-undang Nomor 6 Tahun 2014 tentang Desa

Undang-undang Nomor 32 Tahun 2004 tentang Pemerintahan Daerah

Peraturan Pemerintah No. 72 tahun 2005 tentang desa 
Peratuan Menteri Desa Nomor 4 Tahun 2015 tentang pendirian, pengelolaan dan pembubaran BUMDesa

Peraturan Desa No. 4 tahun 2015 tentang BUMDes

Jaya, Z., Hannan, H. S., \& Khalik, A. (2020, May). ANALSIS PENGEMBANGAN KAPASITAS STRUKTUR ORGANISASI TERHADAP PELAYANAN KESEHATAN DI PUSKESMAS MALUNDA. In Journal Peqguruang: Conference Series (Vol. 2, No. 1).

Muttalib, A., \& Mardawati, M. (2019, November). Efektivitas Media Youtube pada Tayangan Reality Show dalam Menulis Karangan Narasi Peserta Didik Kelas VIII SMP Negeri 3 Malunda. In Journal Peqguruang: Conference Series (Vol. 1, No. 2, pp. 223-228).

Muttalib, A. (2016). Keefektifan Penggunaan Media Pembelajaran Berbasis Audio Visual Dalam Menyusun Teks Puisi Siswa Kelas VII SMP Negeri I Tinambung. Pepatudzu: Media Pendidikan dan Sosial Kemasyarakatan, 9(1), 1-15. 